\title{
A radicalização do debate sobre inclusão escolar no Brasil
}

\author{
Enicéia Gonçalves Mendes \\ Universidade Federal de São Carlos, \\ Programa de Pós-Graduação em Educação Especial
}

\section{Introdução}

A história da educação especial começou a ser traçada no século XVI, com médicos e pedagogos que, desafiando os conceitos vigentes na época, acreditaram nas possibilidades de indivíduos até então considerados ineducáveis. Centrados no aspecto pedagógico, numa sociedade em que a educação formal era direito de poucos, esses precursores desenvolveram seus trabalhos em bases tutoriais, sendo eles próprios os professores de seus pupilos.

Entretanto, apesar de algumas escassas experiências inovadoras desde o século XVI, o cuidado foi meramente custodial, e a institucionalização em asilos e manicômios foi a principal resposta social para tratamento dos considerados desviantes. Foi uma fase de segregação, justificada pela crença de que a pessoa diferente seria mais bem cuidada e protegida se confinada em ambiente separado, também para proteger a sociedade dos "anormais".

Paralelamente à evolução asilar, a institucionalização da escolaridade obrigatória e a incapacidade da escola de responder pela aprendizagem de todos os alunos deram origem, já no século XIX, às classes especiais nas escolas regulares, para onde os alunos difíceis passaram a ser encaminhados.

Assim, o acesso à educação para portadores de deficiências vai sendo muito lentamente conquistado, na medida em que se ampliaram as oportunidades educacionais para a população em geral. Entretanto, tanto as classes quanto as escolas especiais somente iriam proliferar como modalidade alternativa às instituições residenciais depois das duas guerras mundiais.

Na metade do século XX, aparece uma resposta mais ampla da sociedade para os problemas da educação das crianças e jovens com deficiências, em decorrência também da montagem da indústria da reabilitação para tratar dos mutilados da guerra. Até a década de 1970, as provisões educacionais eram voltadas para crianças e jovens que sempre haviam sido impedidos de acessar a escola comum, ou para aqueles que até conseguiam ingressar, mas que passaram a ser encaminhados para classes especiais por não avançarem no processo educacional. A segregação era baseada na crença de que eles seriam mais bem aten- 
didos em suas necessidades educacionais se ensinados em ambientes separados.

Assim, a educação especial foi constituindo-se como um sistema paralelo ao sistema educacional geral, até que, por motivos morais, lógicos, científicos, políticos, econômicos e legais, surgiram as bases para uma proposta de unificação.

Os movimentos sociais pelos direitos humanos, intensificados basicamente na década de 1960, conscientizaram e sensibilizaram a sociedade sobre os prejuízos da segregação e da marginalização de indivíduos de grupos com status minoritários, tornando a segregação sistemática de qualquer grupo ou criança uma prática intolerável. Tal contexto alicerçou uma espécie de base moral para a proposta de integração escolar, sob o argumento irrefutável de que todas as crianças com deficiências teriam o direito inalienável de participar de todos os programas e atividades cotidianas que eram acessíveis para as demais crianças.

Além dos argumentos morais, existiram ainda fundamentos racionais das práticas integradoras, baseados nos seus benefícios tanto para os portadores de deficiências quanto para os colegas sem deficiências. Potenciais benefícios para alunos com deficiências seriam: participar de ambientes de aprendizagem mais desafiadores; ter mais oportunidades para observar e aprender com alunos mais competentes; viver em contextos mais normalizantes e realistas para promover aprendizagens significativas; e ambientes sociais mais facilitadores e responsivos. Benefícios potenciais para os colegas sem deficiências seriam: a possibilidade de ensiná-los a aceitar as diferenças nas formas como as pessoas nascem, crescem e se desenvolvem, e promover neles atitudes de aceitação das próprias potencialidades e limitações.

Um terceiro conjunto de argumentos que fundamentou as práticas integradoras foram as bases empíricas dos achados da pesquisa educacional. Primeiramente, a ciência produziu formas de ensinar pessoas que por muito tempo não foram sequer consideradas educáveis. Posteriormente, a ciência passou a produzir evidências que culminaram numa grande insatis- fação em relação à natureza segregadora e marginalizante dos ambientes de ensino especial nas instituições residenciais, escolas e classes especiais. A partir daí, a constatação de que eles poderiam aprender não era mais suficiente, e passou a ser uma preocupação adicional para a pesquisa investigar "o que", "para que" e "onde" eles poderiam aprender. Adicionalmente, a meta de desenvolver a independência ou autonomia impulsionou a preocupação com a qualidade de vida e com contextos culturais mais normalizantes, a fim de maximizar as possibilidades de desenvolvimento interpessoal e inserção social futura.

Além disso, contribuíram para reforçar o movimento pela integração ações políticas de diferentes grupos organizados, de portadores de deficiências, pais e profissionais, que passaram a exercer forte pressão no intuito de garantir os direitos fundamentais e evitar discriminações.

Um fator também crucial que influenciou a mudança na filosofia de serviços nas décadas de 1960 e 1970 foi o custo elevado dos programas segregados, no contexto da crise mundial do petróleo. Até então, apenas os países considerados desenvolvidos haviam criado um sistema educacional paralelo para os portadores de deficiências. A partir da década de 1960, passou a ser também conveniente adotar a ideologia da integração pela economia que elas representariam para os cofres públicos.

Assim, o contexto histórico da década de 1960 apontava um avanço científico representado tanto pela comprovação das potencialidades educacionais dos portadores de deficiências quanto pelo criticismo científico direcionado aos serviços educacionais existentes. Paralelamente, ocorria a explosão da demanda por ensino especial ocasionada pela incorporação da clientela que, cada vez mais, passou a ser excluída das escolas comuns, fazendo crescer o mercado de empregos dos profissionais especializados e a consolidação da área, o que também ajudou na organização política de grupos que passaram a demandar por mudanças. Isso tudo, associado ao custo alarmante dos programas paralelos especializados que implicavam segregação, num contexto de crise econômica mun- 
dial, permitiu a aglutinação de interesses de políticos, prestadores de serviços, pesquisadores, pais e portadores de deficiências em direção à integração dos portadores de deficiências nos serviços regulares da comunidade.

Esses interesses foram atendidos em diferentes países com o estabelecimento de bases legais que instituíram, gradualmente, a obrigatoriedade do poder público quanto à oferta de oportunidades educacionais para pessoas com deficiências, a instituição da matrícula compulsória nas escolas comuns e de diretrizes para a colocação em serviços educacionais segundo o princípio de restrição ou segregação mínima possível. Assim, estavam estabelecidas as bases para o surgimento da filosofia da normalização e integração, que se tornou ideologia mundialmente dominante basicamente a partir da década de 1970 .

\section{Normalização e integração escolar}

O princípio da normalização teve sua origem nos países escandinavos, com Bank-Mikkelsen (1969) e Nirje (1969), que questionaram o abuso das instituições residenciais e das limitações que esse tipo de serviço sobrepunha em termos de estilo de vida. O princípio tinha como pressuposto básico a idéia de que toda pessoa com deficiência teria o direito inalienável de experienciar um estilo ou padrão de vida que seria comum ou normal em sua cultura, e que a todos indistintamente deveriam ser fornecidas oportunidades iguais de participação em todas as mesmas atividades partilhadas por grupos de idades equivalentes.

O princípio de normalização foi amplamente difundido também na América do Norte e Europa. As subseqüentes implicações desse princípio foram influenciadas pelas propostas de Wolfensberger (1972), que operacionalizou o conceito de "normalização dos estilos de vida" para "normalização de serviços", partindo do pressuposto de que ambientes adequados seriam aqueles vivenciados pelos indivíduos coetâneos considerados normais.
Tal proposta trouxe o desenvolvimento de vários tipos de ações que visavam a integrar essa população na comunidade, com a finalidade de usar meios normativos para promover e/ou manter características, experiências e comportamentos pessoais tão normais quanto possíveis. A definição focalizava a atenção sobre dois aspectos: o que o serviço almejava para seus usuários (comportamentos, experiências e características) e com quais meios isso seria atingido.

A partir de então, houve o uso generalizado do princípio para planejar serviços ao longo das décadas de 1960 e 1970, ocasionando grande movimento de desinstitucionalização, com a retirada das pessoas com deficiências das grandes instituições para reinseri-las na comunidade.

Um medida política que parece ter causado muito impacto na área de educação especial foi a promulgação, em 1977, de uma lei pública nos Estados Unidos (USA, 1977), que assegurou educação pública apropriada para todas as crianças com deficiências, instituindo oficialmente, em âmbito nacional, o processo de mainstreaming. ${ }^{1}$ Tal legislação se constituiu na base jurídica que definia a colocação de indivíduos com deficiências em alternativas minimamente restritivas, e que, conseqüentemente, incentivava a implantação gradual de serviços educacionais na comunidade e desestimulava a institucionalização.

De acordo com os princípios básicos do mainstreaming, a colocação seletiva de estudantes com deficiências deveria levar em consideração os seguintes critérios: 1) preferência pelos serviços educacionais com o mínimo possível de restrição; 2) oferta de serviços educacionais especiais e regulares coordenados; e 3) promoção de situações escolares que favorecessem a convivência com grupos sociais de idades equivalentes (Kirk \& Gallagher, 1979).

\footnotetext{
1 O termo mainstreaming (fluxo, corrente ou tendência prin-
} cipal) foi no Brasil traduzido como integração, mas como os conceitos são diferentes em língua inglesa, optamos por manter a grafia original. 
Desde seu surgimento, o princípio de normalização foi criticado, mais pela incompreensão de que não se tratava de uma teoria científica, mas sim de um princípio filosófico de valor, que estabelecia que todas as pessoas, a despeito de suas inabilidades, deveriam ser tratadas, antes de tudo, como seres humanos plenos. A normalização não era algo para ser feito para uma pessoa, no sentido de tentar normalizá-la, mas sim um princípio que fornecia critérios através dos quais os serviços poderiam ser planejados e avaliados (Mc Cord, 1982).

Em função da confusão relacionada ao significado desse princípio, muitas vezes entendido como uma proposta para "normalizar pessoas", Wolfensberger (1983) tentou substituí-lo pelo termo "valorização do papel social”, com o intuito de enfatizar as metas que seriam promover tanto a imagem social quanto as competências pessoais. Entretanto, o uso do termo normalização popularizou-se e passou a ser amplamente utilizado.

O’Brien (1999) analisou o princípio em cinco dimensões, que seriam: a presença na comunidade, a participação na comunidade, a promoção de habilidades, a promoção da imagem social e a autonomia ou empowerment. ${ }^{2}$ Basicamente, o princípio implicaria prestar serviços assegurando que a pessoa experienciasse dignidade, respeito individual, situações e práticas apropriadas para sua idade, e o máximo possível de participação.

A partir da década de 1970, houve uma mudança, e as escolas comuns passaram a aceitar crianças ou adolescentes deficientes em classes comuns, ou, pelo menos, em classes especiais. Essa filosofia foi amplamente difundida ao longo da década de 1980 no panorama mundial. Epstein (1982), ao estudar os

2 O termo empowerment, embora venha sendo freqüentemente traduzido como empoderamento, não tem uma tradução precisa e foi mantido no original; seu significado neste contexto seria transferir ou devolver o controle da própria vida para a pessoa com deficiência (Charlton, 2000). meios e as metas sobre o princípio de normalização, concluiu que havia consenso geral sobre o princípio em si, mas também desacordo em relação aos meios de operacionalizá-lo.

Deno (1970), considerando a estrutura organizacional dos serviços nos EUA, propôs o sistema em cascata, com diferentes níveis ou graus de integração, envolvendo: 1) classe comum, com ou sem apoio; 2) classe comum associada a serviços suplementares; 3) classe especial em tempo parcial; 4) classe especial em tempo integral; 5) escolas especiais, 6) lares; 7) ambientes hospitalares ou instituições residenciais. Tal sistema pressupunha uma possibilidade de mudança de nível para o aluno, buscando um grau maior de integração escolar com base nas potencialidades e no progresso do aluno.

Outros estudos analisando as várias formas como a proposta de integração escolar estava sendo operacionalizada no Reino Unido (Warnock Report, 1979; ${ }^{3}$ Hegarty, Pocklington \& Lucas, 1981) e na Suécia (Söder, 1980) também indicaram arranjos muito semelhantes na forma de um contínuo de possíveis soluções, o que indica que desde o início do movimento pela integração escolar houve restrição ao uso de uma concepção mais ampliada do conceito de normalização, no sentido de evitar-se a colocação de todo e qualquer aluno na classe comum da escola regular. Também todos os modelos pressupunham a manutenção dos serviços já existentes e uma opção preferencial pela inserção na escola comum, e mais especificamente na classe comum, mas admitindo a necessidade de manter o contínuo de serviços com diferentes níveis de integração.

3 O Relatório Warnock foi um documento apresentado ao Parlamento do Reino Unido, elaborado por um comitê presidido por Mary Warnock, constituído para rever o atendimento aos indivíduos com deficiências na Inglaterra, País de Gales e Escócia. Trata-se de um documento clássico na área, entre outras questões por ter introduzido o conceito de "necessidades educacionais especiais". 
Assim, a integração escolar não era concebida como uma questão de tudo ou nada, mas sim como um processo com vários níveis, através dos quais o sistema educacional proveria os meios mais adequados para atender as necessidades dos alunos. O nível mais adequado seria aquele que melhor favorecesse o desenvolvimento de determinado aluno, em determinado momento e contexto. Percebe-se nessa fase o pressuposto de que as pessoas com deficiências tinham o direito de conviver socialmente, mas que deviam ser, antes de tudo, preparadas em função de suas peculiaridades para assumir papéis na sociedade.

Em 1989, Christie (apud Rosenqvist,1994) explica que a palavra "integração" deriva do latim integrare, do adjetivo integer, que originalmente significava intacto, não tocado, ou íntegro. Entretanto, ao longo da história, a palavra "integração" teve duas derivações de sentido nas línguas modernas. Uma delas é o original, e o outro, o sentido de "compor", "fazer um conjunto", "juntar as partes separadas no sentido de reconstruir uma totalidade". A autora aponta que o conceito de integração escolar, por razões históricas, parece ter assumido o segundo sentido, que seria o da mera colocação de pessoas consideradas deficientes numa mesma escola, mas não necessariamente na mesma classe.

As críticas que surgiram posteriormente ao modelo se basearam na constatação de dois fatos: a passagem de alunos com necessidades educacionais especiais de um nível de serviço mais segregado para outro, supostamente mais integrador, dependia unicamente dos progressos da criança, mas na prática essas transições raramente aconteciam, o que comprometia os pressupostos da integração escolar. Em algumas comunidades, as políticas oficiais de integração escolar resultaram, na maioria das vezes, em práticas quase permanentes de segregação total ou parcial, o que acabou gerando reações mais intensas no sentido de buscar novas formas de assegurar a presença e participação na comunidade, a promoção de habilidades, da imagem social, da autonomia, e o empowerment das pessoas com necessidades educacionais especiais.

\section{Influência norte-americana no debate sobre inclusão escolar ${ }^{4}$}

Analisando-se a literatura sobre inclusão escolar, constata-se que, em geral, sua origem é apontada como iniciativas promovidas por agências multilaterais, que são tomadas como marcos mundiais na história do movimento global de combate à exclusão social. Entretanto, entendemos que essa é uma versão romantizada dessa história, e a tese apresentada aqui é a de que o movimento pela inclusão escolar de crianças e jovens com necessidades educacionais especiais surgiu de forma mais focalizada nos Estados Unidos, e que, por força de penetração da cultura desse país, ganhou a mídia e o mundo ao longo da década de 1990.

Uma evidência disso pode ser constatada no fato de que, até meados da década de 1990, na literatura o termo "inclusão" aparece nos países de língua inglesa, e mais especificamente nos Estados Unidos, enquanto os países europeus ainda conservavam tanto a terminologia "integração" quanto a proposta de colocação seletiva no contínuo de serviços. ${ }^{5}$ Pesquisadores norte-americanos identificaram que o termo "inclusão" apareceu na literatura por volta de 1990, como substituto do termo "integração" e associado à idéia de colocação de alunos com dificuldades prioritariamente nas classes comuns (Sailor, Gee \& Karasoff, 1993; Lipsky \& Gartner, 1997; Turnbull et al., 2002; Sailor, 2002).

A fim de aprofundar um pouco mais a análise, serão descritos os movimentos de reformas ocorridos no sistema educacional dos EUA, antes da popularização mundial do conceito de inclusão escolar.

4 Apesar de ser mais frequiente o uso do termo "educação inclusiva", optamos por questões semânticas pela utilização do termo "inclusão escolar".

5 Ver por exemplo os trabalhos comparativos de Pijl e Meijer (1991), Reynolds e Ainscow (1991), O’Hanlon (1995), Ainscow e Haile-Giorgis (1998), Booth e Ainscow (1998), Evans (2004) e Porter (2004). 
A década de 1980 iria inaugurar uma grande insatisfação entre alguns educadores norte-americanos, principalmente depois de 1983 , com a publicação do estudo "A nation at risk: the imperative educacional reform", ${ }^{6}$ elaborado pela National Commission on Excellence in Education (USA, 1983). Tal documento oferecia um retrato muito pessimista da educação nos EUA, questionando seriamente se no futuro eles seriam capazes de manter sua posição de liderança no contexto mundial. Essa revisão provocou dois momentos seguidos de reforma no sistema educacional geral.

A primeira onda de reforma iniciada na década de 1980 foi denominada "movimento pela excelência na escola". A escola foi identificada como o locus dos problemas educacionais, e mecanismos de controle de desempenho foram criados, baseados em pesquisas sobre os indicadores de qualidade (testes padronizados de desempenho e financiamento controlado pelo ranqueamento das escolas e dos sistemas educacionais baseado nesses indicadores).

Sailor, Gee e Karasoff (1993) relatam que a pesquisa educacional nesse período contribuiu para a introdução de inovações nos currículos e métodos instrucionais, mas que essas mudanças produziram efeitos apenas sobre os melhores estudantes, sem afetar as possibilidades de insucesso e taxas de evasão dos estudantes de risco, que na época compunham cerca de metade da população escolar daquele país.

A segunda onda de reforma, do final da década de 1980, surgiu em parte pela reação às restrições burocráticas impostas às escolas com a exigência de prestação de contas, e tiveram três direções: mudanças nas formas como as escolas eram organizadas, melhoria no status da profissão docente (com aumento de salários, por exemplo) e revisão do sistema de financiamento das escolas, com ênfase na gestão local ou descentralizada dos recursos (inclusive dos re-

6 Que pode ser traduzido como "Uma nação em risco: o imperativo para a reforma educacional". cursos para programas da educação especial). O conjunto desses esforços veio a ser conhecido como "movimento de reestruturação escolar", e teve como alvo melhorar a educação da população de risco.

Sailor, Gee e Karasoff (1993) apontaram que alguns elementos-chave dessa reforma, tais como a revisão curricular, a avaliação baseada no desempenho, a descentralização da instrução, a autonomia organizacional da escola, a gestão e o financiamento centrados na escola, a tomada de decisão compartilhada, a fusão e coordenação dos recursos educacionais e o envolvimento da comunidade, trouxeram implicações para a educação das crianças com necessidades educacionais especiais, na medida em que tais mudanças resultaram em maior flexibilidade para as escolas, que puderam, a partir de então, romper com as práticas tradicionais e aceitar novos desafios. A reestruturação das escolas aumentou também a consciência e o respeito à diversidade, e produziu mudanças no papel da escola, que passou a responder melhor às necessidades de seus diferentes estudantes, provendo recursos variados centrados na própria escola.

$\mathrm{Na}$ educação especial, em contrapartida, a política de integração escolar havia resultado numa estrutura de serviços fragmentada, com função duplicada e nem sempre acessível a todos, sendo que algumas experiências de reestruturação escolar nos EUA, com sua ênfase na organização e gestão com locus na escola, permitiram em alguma proporção racionalizar, democratizar e melhorar o atendimento às necessidades diferenciadas de alunos especiais. ${ }^{7}$

Paralelamente às reformas na educação geral, ocorreram, também na década de 1980, dois movimentos mais focalizados na educação especial, que influenciaram diretamente o aparecimento da proposta

7 Para uma revisão de pesquisas sobre o alinhamento entre os movimentos de reestruturação e a inclusão escolar nos EUA, ver documento publicado em conjunto pela RMC Research Corporation, The Academy for Educational Development, e National Association of State Directors of Special Education (2002). 
de inclusão escolar: o Regular Education Initiative ${ }^{8}$ (Will, 1986) e o Full Inclusion ${ }^{9}$ (Gartner \& Lipsky, 1989; Stainback \& Stainback, 1984).

A proposta contida na "Iniciativa da Educação Regular" surgiu a partir da publicação, em 1986, de um artigo por Madeleine C. Will, que era secretária assistente dos serviços de educação especial e de reabilitação, no qual ela denunciava as limitações da legislação vigente, apontando a necessidade de parcerias entre educação regular e especial, de otimizar os recursos e os serviços educacionais. Com a alegação de que a educação de crianças e jovens com necessidades educacionais especiais deveria ser responsabilidade da educação comum, Will (1986) defendia que todos os alunos deveriam ser inseridos nas classes comuns das escolas comuns, sem descartar a necessidade de manutenção dos serviços de ensino especial separados.

O ponto básico dessa proposta foi a busca pela junção dos recursos da educação regular e especial, a fim de melhor atender estudantes cujas necessidades educacionais eram, principalmente, acadêmicas (Will, 1986). Na prática, ocorreu que crianças com dificuldades de aprendizagem passaram a ser apoiadas na classe comum, ao invés de serem retiradas para receber apoio em classes de recursos, e isso gerou uma grande controvérsia sobre a utilidade da classe de recursos. Entretanto, essa prática não foi bem aceita pela comunidade educacional e, segundo Scruggs e Mastropieri (1993), essa política do Governo Reagan resultou no enfraquecimento das garantias legais da população da educação especial, e reavivou o debate a favor e contra os programas de educação especial separados da educação regular.

Além do modelo derivado da "iniciativa da educação regular", surgiu a proposta de "inclusão total"

8 O termo Regular Education Initiative (REI) será aqui traduzido como "Iniciativa da Educação Regular".

9 O termo full inclusion será traduzido neste artigo como “inclusão total”, no sentido de ser uma abordagem mais radical em favor de uma inclusão que seja total, integral ou plena.
(Gartner \& Lipsky, 1989; Stainback \& Stainback, 1984), que se configurava de forma mais radical, no sentido de estabelecer um tipo de política sem exceção, requisitando a participação em tempo integral na classe comum apropriada à idade, para todos os estudantes, a despeito do quão extensivas fossem suas limitações. A proposta estava fundamentada na ética da participação e do desenvolvimento social sem a preocupação com ganhos acadêmicos. Tal proposta surgiu no âmbito dos que defendiam os direitos dos indivíduos com graus mais severos de limitação intelectual, que foi a clientela para a qual os modelos de integração escolar foram mais prejudiciais, dado que eles continuavam vivenciando experiências segregadoras no processo educacional, e sendo excluídos das classes comuns e das escolas regulares. Muito da argumentação para a inclusão total foi impelida pela confiança no direito cível contra a segregação de estudantes com base em suas deficiências, um tema que estava tendo reflexo em várias decisões importantes em processos judiciais cujos julgamentos acabavam favorecendo práticas de colocação inclusiva.

Percebe-se que há alguns pontos comuns entre essas duas iniciativas, pois ambas tiveram suas origens no movimento pela integração escolar e buscavam a fusão dos sistemas de ensino regular e especial. A idéia central era a de que, além de intervir diretamente sobre essas pessoas, se fazia necessário mudar também a escola, para que esta possibilitasse a convivência dos diferentes. No âmbito da educação, passou-se a defender um único sistema educacional de qualidade para todos os alunos, com ou sem deficiência. Entretanto, a "Iniciativa da Educação Regular" tinha como população-alvo os indivíduos com limitações leves ou no máximo moderadas, enquanto a "inclusão total" era defendida pelos advogados dos direitos dos portadores de deficiências mais severas (Sale \& Carey, 1995).

Assim, os movimentos da educação geral e da educação especial nos Estados Unidos, que antes eram empreendimentos de forma isolada, passaram a poder partilhar uma mesma agenda de reformas, principalmente após o movimento de reestruturação esco- 
lar. Entretanto, o movimento naquele país logo se bifurcou em pelo menos duas principais correntes, com propostas divergentes sobre qual seria a melhor forma de educar crianças e jovens com necessidades educacionais especiais: a proposta de "educação inclusiva" e a da "inclusão total" (Sailor, 2002).

Sailor (2002) aponta que o termo "educação inclusiva" emergiu também no início da década de 1990, e embora tivesse implicações políticas semelhantes às do termo "inclusão", seu foco era mais na escola do que na sala de aula. A "educação inclusiva” pressupunha a colocação de todos os estudantes como membros de uma classe comum, mas deixava abertas as oportunidades para estudantes serem ensinados em outros ambientes na escola e na comunidade. A retirada da criança da classe comum seria possível nos casos em que seus planos educacionais individualizados previssem que seria improvável derivar benefícios educacionais da participação exclusiva na classe comum.

A partir de então, aparecem na literatura duas posições mais extremistas, estando num dos extremos a proposta de inclusão total, que advoga a colocação de todos os estudantes, independentemente do grau e tipo de incapacidade, na classe comum da escola próxima à sua residência, e a eliminação total do atual modelo de prestação baseado num contínuo de serviços de apoio de ensino especial. Do outro lado estão os adeptos da educação inclusiva, que consideram que a melhor colocação seria sempre na classe comum, embora admitindo a possibilidade de serviços de suportes, ou mesmo ambientes diferenciados (tais como classes de recursos, classes especiais parciais ou autocontidas, escolas especiais ou residenciais).

Fuchs e Fuchs (1998), analisando a realidade de seu país, estabeleceram as seguintes diferenças entre as propostas de inclusão escolar e de inclusão total:

a) Os "inclusionistas" consideram que o objetivo principal da escola é auxiliar o aluno a dominar habilidades e conhecimentos necessários para a vida futura, tanto dentro quanto fora da escola, enquanto os "inclusionistas totais" acreditam que as escolas são impor- tantes mais pelas oportunidades que oferecem para fazer amizades, para mudar o pensamento estereotipado sobre as incapacidades e para fortalecer as habilidades de socialização;

b) Os "inclusionistas" defendem a manutenção do contínuo de serviços que permite a colocação desde a classe comum até os serviços hospitalares, enquanto os "inclusionistas totais" advogam pela colocação apenas e só na classe comum da escola regular, e pregam ainda a necessidade de extinção do contínuo;

c) Os "inclusionistas" acreditam que a capacidade de mudança da classe comum é finita, e mesmo que uma reestruturação ocorra a escola comum não será adequada a todas as crianças, ao passo que os "inclusionistas totais" crêem na possibilidade de reinventar a escola a fim de acomodar todas as dimensões da diversidade da espécie humana.

Paralelamente a esse embate sobre as diferentes formas de se conceber as diretrizes de uma política de inclusão escolar nos sistemas de ensino, que vai se prolongar ao longo da década de 1990, chegando até a atualidade, observa-se o surgimento de um contexto histórico mundial que passou a reforçar cada vez mais a ideologia da educação inclusiva, que, embora pareça historicamente ter surgido de forma mais organizada nos Estados Unidos, ganhou a mídia e o mundo a partir da metade da década de 1990.

\section{Marcos mundiais da educação inclusiva ${ }^{10}$}

Em 1990, foi realizada a Conferência Mundial sobre Educação para Todos: satisfação das necessidades básicas de aprendizagem, em Jomtien, Tailândia, promovida pelo Banco Mundial, Organi-

${ }^{10}$ A utilização do termo "educação inclusiva" nesta parte do texto é proposital, para ser fiel à terminologia dos documentos internacionais que irão popularizar o conceito. 
zação das Nações Unidas para a Educação, a Ciência e a Cultura (UNESCO), Fundo das Nações Unidas para a Infância (UNICEF) e Programa das Nações Unidas para o Desenvolvimento (PNUD). Participaram educadores de diversos países do mundo, sendo nessa ocasião aprovada a Declaração Mundial sobre Educação para Todos.

Nos países pobres e em desenvolvimento, as estatísticas do início da década de 1990 apontavam que mais de 100 milhões de crianças e jovens não tinham acesso à escolarização básica; e que apenas $2 \%$ de uma população com deficiência, estimada em 600 milhões de pessoas, recebia qualquer modalidade de educação. Tais evidências estimularam o consenso sobre a necessidade de concentrar esforços para atender as necessidades educacionais de inúmeros alunos até então privados do direito de acesso, ingresso, permanência e sucesso na escola básica (Declaração Mundial sobre Educação para Todos, 1990).

Em 1994, promovida pelo governo da Espanha e pela UNESCO, foi realizada a Conferência Mundial sobre Necessidades Educacionais Especiais: acesso e qualidade, que produziu a Declaração de Salamanca (Brasil, 1997), tida como o mais importante marco mundial na difusão da filosofia da educação inclusiva. A partir de então, ganham terreno as teorias e práticas inclusivas em muitos países, inclusive no Brasil.

No contexto mundial, o princípio da inclusão passa então a ser defendido como uma proposta da aplicação prática ao campo da educação de um movimento mundial, denominado inclusão social, que implicaria a construção de um processo bilateral no qual as pessoas excluídas e a sociedade buscam, em parceria, efetivar a equiparação de oportunidades para todos, construindo uma sociedade democrática na qual todos conquistariam sua cidadania, na qual a diversidade seria respeitada e haveria aceitação e reconhecimento político das diferenças.

Num contexto em que uma sociedade inclusiva passa a ser considerada um processo de fundamental importância para o desenvolvimento e a manutenção do estado democrático, a educação inclusiva começa a configurar-se como parte integrante e essencial desse processo. Dessa forma, o paradigma da inclusão globaliza-se e torna-se, no final do século XX, palavra de ordem em praticamente todas as ciências humanas.

Portanto, não é nova a idéia de que seria melhor incorporar crianças com necessidades educacionais especiais na escola comum, pois estava presente desde o movimento pela integração escolar, que, entretanto, entendia que o problema estava centrado nas crianças e deixava implícita uma visão acrítica da escola, por pressupor que as escolas comuns conseguiam educar pelo menos os considerados normais (Bueno, 2001). A inclusão, em contrapartida, estabelecia que as diferenças humanas eram normais, mas ao mesmo tempo reconhecia que a escola estava provocando ou acentuando desigualdades associadas à existência das diferenças de origem pessoal, social, cultural e política, e por isso pregava a necessidade de reforma educacional para prover uma educação de qualidade para todas as crianças.

Peter Mittler (apud Martins, 1999) acrescenta que na perspectiva da integração não havia pressuposição de mudança da escola, ao passo que a inclusão estabelecia necessidade de reformulação dos currículos, das formas de avaliação, da formação dos professores e a adoção de uma política educacional mais democrática.

Ao mesmo tempo em que o ideal da inclusão se globaliza e se torna pauta de discussão obrigatória para todos os interessados nos direitos dos alunos com necessidades educacionais especiais, são renovadas velhas controvérsias, que estavam também presentes no ideário da integração escolar, e que se referem às formas de efetivá-la. Ferguson e Ferguson (1998) apontam os seguintes conflitos acerca da inclusão escolar de alunos com necessidades educacionais especiais: a) a inclusão é para todos, ou só para alguns?; b) a inclusão significa colocação integral na classe comum ou pode-se combinar a colocação na classe comum com situações especializadas de aprendizagem?; c) a inclusão prioriza a aprendizagem social e as amizades ou o desempenho acadêmico bemsucedido?; d) a inclusão será prejudicial ou positiva para os alunos sem limitações?; e) as evidências empíricas sustentam ou não a inclusão? 
Os autores consideram que, subjacente a algumas dessas tensões presentes na atual retórica sobre a inclusão escolar, se encontra o antigo dilema sobre qual é a natureza e o propósito da escolarização em si, e que, enquanto a inclusão poderia ser parte de um debate maior sobre a função da escola, ela ainda se detém muito em onde e como os indivíduos podem aprender melhor.

Em resumo, ao longo dos últimos trinta anos, tem-se assistido a um grande debate acerca das vantagens e desvantagens, antes, da integração escolar, e, mais recentemente, da inclusão escolar. A questão sobre qual é a melhor forma de educar crianças e jovens com necessidades educacionais especiais não tem resposta ou receita pronta. $\mathrm{Na}$ atualidade, as propostas variam desde a idéia da inclusão total - posição que defende que todos os alunos devem ser educados apenas e só na classe da escola regular - até a idéia de que a diversidade de características implica a existência e manutenção de um contínuo de serviços e de uma diversidade de opções.

Hallahan e Kauffman (1994) apontam que a proposta de "inclusão total" ainda hoje sofre considerável resistência, com base nos seguintes argumentos:

a) há muitos pais, professores (tanto do ensino regular quanto do especial), especialistas e os próprios educandos, que estão satisfeitos com os serviços baseados no continuum;

b) para alguns tipos de dificuldade (como as deficiências graves, os graves problemas comportamentais ou as desordens sérias na comunicação) pode ser mais restritiva e segregadora a sala de aula comum do que um tipo de colocação mais protegida e estruturada;

c) nem todos os professores e educadores do ensino regular estão dispostos a, ou mesmo são capazes de lidar com todos os tipos de alunos com dificuldades especiais, principalmente com os casos de menor incidência - mas de maior gravidade - que exigem recursos técnicos e serviços diferenciados de apoio; d) a afirmação de que as pessoas deficientes compõem um grupo minoritário em luta pelos seus direitos civis, como qualquer outra minoria oprimida e segregada, é um argumento falacioso para sustentar a defesa da "inclusão total", porque, além de grupo minoritário, eles têm dificuldades centradas nos seus mecanismos de aprendizagem e precisam de respostas educacionais diferenciadas, nem sempre disponíveis na classe comum;

e) um dos principais direitos de qualquer minoria é o seu direito de escolha, sendo que os pais ou tutores desses alunos devem ter liberdade para escolher o que acham melhor para os seus filhos;

f) desconsiderar a evidência empírica de que há eficácia em alguns tipos de resposta mais protegida, para alguns tipos de alunos com dificuldades especiais na escola, seria uma atitude profissionalmente irresponsável e antiética;

g) na ausência de dados que suportem a vantagem do modelo, os educadores e políticos deveriam preservar o contínuo de serviços, para que, em qualquer momento, seja salvaguardada a escolha daquele que se mostrar menos restritivo para as circunstâncias.

Enfim, sob a bandeira da inclusão são encontrados, na atualidade, práticas e pressupostos bastante distintos, o que garante um consenso apenas aparente e acomoda diferentes posições que podem ser extremamente divergentes. Uma tomada de posição consciente dentro desse conjunto de possibilidades deve começar pelo entendimento que se tem acerca do princípio da inclusão escolar, lembrando que o termo assume atualmente o significado que quem o utiliza deseja. E como se configura a discussão desta temática no Brasil?

\section{Perspectivas da inclusão escolar na realidade brasileira}

No Brasil, iniciativas isoladas e precursoras de educação de indivíduos com necessidades educacio- 
nais especiais podem ser constatadas já no século XIX, e, acompanhando a tendência da época, em instituições residenciais e hospitais - portanto, fora do sistema de educação geral que aos poucos se iria constituindo no país.

Durante a década de 1950, a escassez de serviços e o descaso do poder público deram origem a movimentos comunitários que culminaram com a implantação de redes de escolas especiais privadas filantrópicas para aqueles que sempre estiveram excluídos das escolas comuns (Jannuzzi, 2004). Entretanto, é muito provável que algumas crianças com alguns tipos mais brandos de deficiência tenham sempre tido alguma oportunidade de acesso à escola comum, um fenômeno que a literatura vem apontando como de integração espontânea ou não-planejada, encontrada em países com cobertura deficitária (Odeh, 2000; Krause, 2002).

Foi apenas na década de 1970 que surgiu uma resposta mais contundente do poder público a essa questão (Ferreira, 1994; Mazzotta, 1994; Jannuzzi, 2004). Possivelmente esse avanço foi decorrência da ampliação do acesso à escola para a população em geral, da produção do fracasso escolar e da conseqüente implantação das classes especiais nas escolas básicas públicas, na época predominantemente sob a responsabilidade dos sistemas estaduais (Ferreira, 1994).

Assim, o início da institucionalização da educação especial em nosso país coincidiu com o auge da hegemonia da filosofia da "normalização" no contexto mundial, e passamos a partir de então a atuar, por cerca de trinta anos, sob o princípio de "integração escolar", até que emergiu o discurso em defesa da "educação inclusiva", a partir de meados da década de 1990.

Os resultados dos trinta anos da política de "integração escolar" tiveram como maior impacto o fortalecimento do processo de exclusão na escola pública de crianças consideradas indesejadas pela escola comum, que eram encaminhadas para as classes especiais (Bueno, 1993). O modelo que previa uma opção preferencial pela inserção na classe comum com a manutenção do contínuo de serviços nunca chegou de fato a ser implementado na "integração escolar" à moda brasileira, visto que ainda hoje os recursos predominantes são as classes especiais nas escolas públicas e as escolas especiais, notadamente as privadas e filantrópicas.

Estima-se que existam no país cerca de seis milhões de crianças e jovens com necessidades educacionais especiais, ${ }^{11}$ para um contingente oficial de matrículas em torno de 500 mil alunos (Brasil, 2003), considerando o conjunto de matrículas em todos os tipos de recursos disponíveis (desde escolas especiais até escolas e classes comuns). Portanto, a grande maioria dos alunos com necessidades educacionais especiais encontra-se hoje fora de qualquer tipo de escola, o que configura muito mais uma exclusão generalizada da escola, a despeito da anterior retórica da integração e/ou da recente proposta de inclusão escolar.

As mazelas da educação especial brasileira, entretanto, não se limitam à falta de acesso. Os poucos alunos que têm tido acesso não estão necessariamente recebendo uma educação apropriada, seja por falta de profissionais qualificados ou mesmo pela falta generalizada de recursos. Além da predominância de serviços que envolvem, desnecessariamente, a segregação escolar, há evidências que indicam um descaso do poder público, uma tendência de privatização (considerando que a maioria das matrículas está concentrada na rede privada, mais especificamente em instituições filantrópicas) e uma lenta evolução no crescimento da oferta de matrículas, em comparação com a demanda existente.

A Constituição Federal de 1988 (Brasil, 1988) e as Diretrizes e Bases da Educação Nacional - Lei n. 9.394/96 (Brasil, 1996) - estabelecem que a educa-

11 Tal estimativa não é facilmente encontrada nos documentos oficiais; essa informação foi extraída de uma reportagem publicada no jornal Folha de S. Paulo de 11 de junho de 1999, cuja fonte noticiada foi o Ministério da Educação. 
ção é direito de todos e que as pessoas com necessidades educacionais especiais devem ter atendimento educacional "preferencialmente na rede regular de ensino", garantindo atendimento educacional especializado aos portadores de deficiência. A legislação, ao mesmo tempo em que ampara a possibilidade de acesso à escola comum, não define obrigatoriedade e até admite a possibilidade de escolarização que não seja na escola regular.

As estatísticas oficiais apontam que de 1996 a 2003 houve um incremento da cobertura da ordem de $150,6 \%$, e que, das 504.039 matrículas, 55,5\% ainda se concentravam em escolas especializadas e $15,6 \%$ em classes especiais. Das matrículas em classes comuns, havia 63.766 educandos (12,5\%) com apoio de salas de recursos e 81.375 educandos $(16,4 \%)$ freqüentando exclusivamente classes comuns (Brasil, 2003).

Analisando-se a evolução das matrículas por dependência administrativa nos anos de 1996 a 2003, observa-se uma tendência à municipalização, indicada pelo incremento percentual de $389 \%$ na rede municipal, contra $185 \%$ na rede particular, $44 \%$ na rede estadual e um decréscimo de 13,8\% nas matrículas na rede federal.

Os dados oficiais apontavam ainda que houve nesse mesmo período (de 1996 a 2003) um crescimento de matrículas de $242 \%$ para estudantes superdotados/com altas habilidades, $210 \%$ para alunos com deficiência física, $200 \%$ para alunos com deficiência visual, $165 \%$ para alunos com deficiência múltipla, $108 \%$ para alunos com deficiência intelectual, $83,2 \%$ para alunos com deficiência auditiva e de $77 \%$ para estudantes com as condutas típicas de síndromes. Entretanto, os dados de 2003 apontam que o aumento mais expressivo nas matrículas foi encontrado numa categoria genérica denominada "outras", na qual foram enquadradas 66.850 pessoas (cerca de $13 \%$ do total dos estudantes notificados como especiais), sendo que tal categoria não foi considerada nos dados de 1996.

Em resumo, ainda que se observasse um aumento nas matrículas tomando-se como base os dados oficiais, o que não é o caso, não há evidências de que as diretrizes políticas anunciadas pelos sistemas públicos de ensino estejam sendo bem-sucedidas, porque:

a) houve um aumento muito discreto na cobertura em relação à demanda em potencial;

b) a maioria continua à margem de qualquer tipo de escola;

c) os que conseguem acesso ainda estão majoritariamente em escolas especiais privadas filantrópicas, ou no máximo em classes especiais de escolas comuns;

d) os dados oficiais são imprecisos porque os procedimentos de identificação de alunos adotados no censo escolar não são confiáveis, na medida em que não há no país diretrizes claras para a notificação, e muito menos para a classificação categorial;

e) a alta proporção de alunos enquadrados na categoria "outros" parece indicar que a estatística foi inflacionada com alunos que não estavam antes sendo contabilizados, e que provavelmente já tinham acesso à escola, mesmo antes do anúncio oficial de políticas de inclusão escolar; sendo que esse alto contingente nessa categoria residual evidencia indefinição atual de quem é a população de alunos com necessidades educacionais especiais;

f) o incremento percentual das matrículas de alunos com quadros de deficiências deve ser ponderado em razão do reduzido número de matrículas em 1996, e também pelo fato de a maioria se enquadrar na condição de deficiência mental, que é a condição cujo diagnóstico é bastante complicado na realidade brasileira.

Assim, embora se perceba que o debate acerca da inclusão escolar vem sendo um assunto recorrente, nem mesmo a matrícula de alunos com necessidades educacionais especiais, uma garantia legal alcançada há mais de 17 anos, parece estar avançando.

Numa revisão da produção científica na forma de dissertações e teses sobre a temática, Mendes, Ferreira e Nunes (2003) apontaram que os poucos 
dados empíricos disponíveis se restringem muito a relatos de depoimentos, de experiências, e em estudos de casos, que não permitem ainda avaliar o impacto da política educacional. No geral, os estudos nacionais indicam que, mesmo para as poucas matrículas existentes, faltam aspectos básicos para garantir não apenas o acesso, mas a permanência e o sucesso desses alunos com necessidades educacionais especiais matriculados em classes comuns.

No âmbito dos sistemas estaduais e municipais, diretrizes políticas de reforma norteadas pelos princípios da inclusão escolar estão sendo anunciadas, mas em geral observa-se a ausência de procedimentos de avaliação, o que compromete o processo de implementação das propostas. Faltam indicadores para monitorar o processo, os que acenam com estatísticas promissoras muitas vezes não possuem dados confiáveis, e outras vezes não complementam seus estudos com descrições de quem é esse alunado e de como está sua situação educacional - ou, mais especificamente, se eles estão tendo acesso ao currículo, se estão socializando na direção desejável e se estão sendo socialmente aceitos na escola (Santos, 2002; Rosa, 2003; Mendes, Ferreira \& Nunes, 2003).

Uma fonte recente de entraves para a evolução da política de inclusão escolar no Brasil parece estar originando-se de algumas intervenções da Secretaria de Educação Especial (SEESP) do Ministério da Educação, que tradicionalmente sempre assumiu papel fundamental nos rumos da educação especial no país. Nota-se que após a implantação deste órgão, na década de 1970, houve uma fase de incentivo explícito à iniciativa privada e ao assistencialismo das organizações não-governamentais (Mazzotta, 1994; Jannuzzi, 2004). Posteriormente, o sistema paralelo foi reforçado na medida em que os estados brasileiros foram incentivados a criar órgãos de gestão junto às secretarias de educação, quando o Ministério da Educação começou a repassar regularmente verbas para incentivar a formação de professores especializados, e isso fortaleceu a implantação de classes especiais nas escolas públicas estaduais (Ferreira, 1994; Mattos, 2004; Jannuzzi, 2004).
Na gestão política do atual governo, a SEESP, ignorando o aporte que se teve no país com o debate acerca da inclusão escolar na última metade da década de 1990, e desafiando o pressuposto de que uma política tenha de ser um processo de construção coletiva, tem tentado consistentemente impingir aos sistemas uma diretriz política nada consensual, que é mais fundamentada no princípio da inclusão total.

Uma ação que indica a radicalização da condução da política tem sido as várias tentativas de produzir alterações na Resolução n. 2/2001 do Conselho Nacional de Educação (CNE) (Brasil, 2001), documento construído com a participação da sociedade civil. A resposta contida no Parecer n. 4/2002 do CNE (Brasil, 2002) considerou improcedente a necessidade de revisão da referida resolução (Cury, 2005), mas a SEESP continua mantendo esforços para alterar esse documento, sem envolver a participação da comunidade interessada no assunto.

Ainda a pretexto de promover a educação inclusiva, a SEESP tem investido no Programa de Educação Inclusiva: Direito à Diversidade, oferecendo pacotes fechados para gestores multiplicadores, que são capacitados em Brasília durante uma semana, recebendo um conjunto de apostilas prontas, e seguindo para servir como pólo de disseminação da política de inclusão em suas regiões. Segundo informações encontradas no sítio da SEESP, no portal do Ministério da Educação (MEC), o programa já atingiu 15 mil educadores de todos os estados e Distrito Federal, 144 municípios-pólo que atuam como multiplicadores para outros 2.583 municípios da sua área de abrangência (Brasil, 2005). A meta do programa em 2006 é atingir 4.646 municípios (83,5\% dos municípios brasileiros).

Fuller e Clarck (1994) apontam que uma das falhas freqüentes das propostas políticas de inclusão escolar tem sido a tendência de tentar padronizar o processo, como se fosse possível desenvolver uma perspectiva nacional única, ou prescrever padrões para contextos locais, como os sistemas estaduais ou municipais, desconsiderando os efeitos que suas histórias assumem sobre a prática e a política. 
Uma terceira iniciativa da SEESP foi o apoio à publicação de um documento do Ministério Público Federal - $O$ acesso de alunos com deficiência às escolas e classes comuns da rede regular (Brasil, 2004) - que reforça os pressupostos da inclusão total, desconsiderando assim a posição de grande parte dos pesquisadores, prestadores de serviços, das famílias e dos próprios indivíduos com necessidades educacionais especiais.

Assim, as ações da política do MEC têm prejudicado o processo de construção da inclusão escolar na realidade brasileira, entre outros motivos porque:

a) Transformaram o debate em embate, produzindo divisão no movimento histórico de luta pelo direito à educação de pessoas com necessidades educacionais especiais, quando deveria promover a integração entre as ações do poder público e da sociedade civil.

b) Têm tentado impor uma concepção única de política de inclusão, que sequer é consensual, o que tem dificultado a compreensão por parte dos atores desse movimento e, conseqüentemente, tem aumentado a resistência à política de inclusão escolar que o sistema requer.

c) Deslocaram o debate de seu cerne, que seria como melhorar a qualidade da educação brasileira para todos os alunos indistintamente, para centralizar na questão de onde os alunos com necessidades educacionais especiais deverão estudar.

d) Priorizaram a opinião de juristas sobre qual é a melhor opção para a escolarização de crianças com necessidades educacionais especiais, desconsiderando a história e a opinião dos próprios portadores de deficiências, suas famílias, educadores, cientistas e prestadores de serviços.

e) Têm escalado a educação especial como protagonista, ao invés de manter seu papel de coadjuvante colaboradora, numa reforma que deveria ser iniciativa da educação comum.
A consequiência dessa política nacional no âmbito dos estados e municípios tem sido guiada mais pela atratividade do baixo custo, pois a curto prazo a ideologia da inclusão total traz vantagens financeiras, porque justifica tanto o fechamento de programas e serviços nas escolas públicas (como as classes especiais ou salas de recursos), quanto a diminuição do financiamento às escolas especiais filantrópicas. A médio e longo prazos, ela permite ainda deixar de custear medidas tais como a formação continuada de professores especializados, mudanças na organização e gestão de pessoal e no financiamento para atender diferencialmente o alunado com necessidades educacionais especiais.

Na história da educação especial, em todos os tempos, sempre houve adeptos das propostas integracionistas. Entretanto, elas emergem como ideologia hegemônica justamente em momentos históricos nos quais a exclusão social se intensifica. O movimento pela normalização e integração social, por exemplo, surgiu concomitantemente à depressão econômica decorrente da crise do petróleo, por volta da década de 1970, e serviu para fechar instituições e reduzir gastos. A atual proposta de inclusão emergiu no final da década de 1980, quando o modelo econômico vigente passou a atingir níveis insuportáveis de exclusão social.

Portanto, os determinantes econômicos têm servido como poderosos propulsores do movimento de inclusão, e têm transformado movimentos sociais legítimos de resistência em justificativas veladas para cortar gastos dos programas sociais, diminuindo assim o papel do Estado nas políticas sociais.

O perigo dessa contradição tem sido consideravelmente maior nas propostas de inclusão total, que ainda é uma estratégia política controvertida. Fuchs e Fuchs (1994) alertam que se trata de uma resposta muito simplista e equivocada a um tema demasiadamente complexo, e que ainda está muito mais baseada em crença ou convicção pessoal e numa confiança excessiva na retórica, quando faltam evidências científicas capazes de sustentá-la.

Assim, precisamos na atualidade ir além dos argumentos ideológicos, do romantismo, da ilusão de que será um processo fácil, barato e indolor, se qui- 
sermos avançar de fato em direção a um sistema educacional mais inclusivo, e escrutinar continuamente se não estamos produzindo, sob a bandeira da inclusão, formas cada vez mais sutis de exclusão escolar.

Enfim, ao analisarmos a política de inclusão escolar como política pública setorizada no campo da educação, podemos encontrar evidências suficientes para prever seu fracasso. Ao contextualizarmos essa política educacional no conjunto de outras políticas públicas, também setorizadas, para combater a lógica da exclusão social, a probabilidade de insucesso amplia-se consideravelmente, pois não há como construir uma escola inclusiva num país com tamanha desigualdade, fruto de uma das piores sistemáticas de distribuição de renda do planeta.

No Brasil, no campo educacional, as perspectivas para a mudança estão postas na lei, mas ainda não estão devidamente traduzidas em ações políticas, e por isso nem chegam às escolas, e menos ainda às salas de aula. O poder público não está cumprindo bem sua função, o que não impede que cada um assuma sua parte e se torne sujeito dessa história.

\section{Conclusão}

Este texto sustenta que as raízes históricas da emergência do caloroso debate acerca da inclusão escolar em nosso país é fruto de mais uma adoção ao modismo importado, e, especificamente, mais uma influência da cultura norte-americana, que tem demarcado até mesmo a forma que o movimento vem assumindo no Brasil, o que se evidencia em três semelhanças:

a) na dicotomização do debate entre educação inclusiva $x$ inclusão total;

b) na interpretação equivocada e reducionista de que educação inclusiva é algo que diz respeito exclusivamente à população tradicional da educação especial, e não ao conjunto dos excluídos; e, finalmente,

c) na influência de juristas na definição da política de educação para crianças e jovens com necessidades educacionais especiais.
O movimento seria mais legítimo e teria maior possibilidade de sucesso se tivesse como lastro uma história própria de conquistas e lutas pelo direito à educação das crianças e jovens com necessidades educacionais especiais. Infelizmente, essa não é a nossa realidade.

Mas, ao mesmo tempo, não há como negar que a grande maioria das nossas crianças e jovens com necessidades educacionais especiais permanece à margem de qualquer tipo de escola, e que nesse contexto a posição de ir radicalmente contra a inclusão escolar é muito perigosa, pois pode implicar a impossibilidade de universalizar o acesso à educação para essa parcela da população que vem sendo historicamente excluída de nossas escolas.

Se de fato a facilidade de acesso à escola regular e à classe comum, mesmo que restrita ao âmbito legal, se configura como um momento ímpar na história, ela não pode ser descartada como estratégia de democratização do acesso. Além disso, não há como melhorar nossas escolas se as diferenças continuarem a ser sistematicamente delas excluídas.

O paradoxo torna-se então lidar com uma ideologia que é importada, sendo que sua adoção, ao mesmo tempo em que representa um alinhamento ao modismo, é também uma questão de valor e portanto de um imperativo moral para as sociedades democráticas. Além disso, não se pode negar a conotação política do movimento pela inclusão escolar como estratégia potencial para ampliar o acesso à escola pública para crianças e jovens com necessidades educacionais especiais, e talvez de promover o avanço necessário na educação especial e da educação em geral no país.

Considerando, entretanto, que o conceito de inclusão escolar é ambíguo, porque ele assume o significado dentro de contextos históricos determinados que lhe dão definição, conclui-se também que cada comunidade deve buscar a melhor forma de definir e fazer a sua própria política de inclusão escolar, respeitando as bases históricas, legais, filosóficas, políticas e também econômicas do contexto no qual ela irá efetivar-se. 
Se o termo surgiu no início da década de 1990 e veio associado a uma prática de colocação de alunos com dificuldades prioritariamente nas classes comuns, hoje o seu significado aparece ampliado, englobando também a noção de inserção de apoios, serviços e suportes nas escolas regulares, indicando que a inclusão bem-sucedida implica financiamento.

De modo geral, pode-se concluir que o debate sobre o princípio da inclusão escolar no Brasil é hoje um fenômeno da retórica, como foi a integração escolar nos últimos trinta anos. Ainda estamos na luta pelo acesso, e este deve ser direcionado necessariamente para aumentar as matrículas nas classes comuns das escolas públicas do ensino regular.

Entretanto, só o acesso não é suficiente, e traduzir a filosofia de inclusão das leis, dos planos e das intenções para a realidade dos sistemas e das escolas requer conhecimento e prática. É preciso, portanto, questionar: Qual a prática necessária? E o conhecimento necessário para fundamentar a prática? E este é, sem dúvida nenhuma, um exercício para a pesquisa científica.

Assim, a ciência será essencial para que a sociedade brasileira busque contribuir, de maneira intencional e planejada, para a superação de uma educação que tem atuado contra os ideais de inclusão social e plena cidadania. É necessário que se faça uma pesquisa mais engajada nos problemas da realidade e que tenham implicações práticas e políticas mais claras. Em contrapartida, é necessário também que o processo de tomada de decisão política privilegie mais as bases empíricas fornecidas pela pesquisa científica sobre inclusão escolar na nossa realidade.

A mudança requer ainda um potencial instalado, em termos de recursos humanos, em condições de trabalho, para que ela possa ser posta em prática; e este é um desafio considerável para o sistema brasileiro de ensino superior.

Enfim, o futuro da inclusão escolar em nosso país dependerá de um esforço coletivo, que obrigará a uma revisão na postura de pesquisadores, políticos, prestadores de serviços, familiares e indivíduos com necessidades educacionais especiais, para trabalhar numa meta comum, que seria a de garantir uma educação de melhor qualidade para todos.

Politicamente, o movimento pela inclusão escolar requer certos cuidados e definições mais precisas, caso contrário terá o mesmo destino da "integração escolar", ou seja, corremos o sério risco de perseverar na retórica, na eterna ponderação de que estamos apenas começando um processo, até que venha, no futuro, um novo "paradigma" redentor, do exterior provavelmente, que irá "revolucionar" nosso discurso e quiçá um dia transformar nossas escolas.

\section{Referências bibliográficas}

AINSCOW, Mel; HAILE-GIORGIS, Memmenasha. The education of children with special needs: barriers and opportunities in Central and Eastern Europe. Florence: UNICEF International Child Development Centre, 1998 (Innocenti Occasional Papers, Economic and Social Policy Series n. 67).

BANK-MIKKELSEN, Neils Erik. A Metropolitan area in Denmark: Copenhagen. In: R. KUGEL, Robert B.; WOLFENSBERGER, Wolf (Eds.). Changing patterns in residential services for the mentally retarded. Washington: President's Committee on Mental Retardation, 1969. Disponível em: <http://www.disabilitymuseum.org/lib/docs/ 1942.htm>. Acesso em: 12 dez. 2005.

BOOTH, Tony; AINSCOW, Mel. (Eds.). From then to us: an international study of inclusion in education. London: Routledge, 1998.

BRASIL, Assembléia Nacional Constituinte. Constituição da República Federativa do Brasil. Brasília, DF: Senado Federal/Secretaria Especial de Editoração e Publicações, 1988.

BRASIL, Congresso Nacional. Lei n. 9.394, de 20 de dezembro de 1996. Estabelece as diretrizes e bases da educação nacional. Diário Oficial da União n. 248, de 23/12/96 - Seção I, p. 27833. Brasília, 1996.

BRASIL, Ministério da Educação, Conselho Nacional de Educação. Câmara de Educação Básica. Resolução CNE/CEB 2/2001. Diário Oficial da União, Brasília, 14 de setembro de 2001. Seção 1E, p. 39-40. 2001.

Parecer CNE/CEB n. 4/2002. Diário Oficial da

União, Brasília, 22 de fevereiro de 2002, Seção 1, p. 23. 2002.

BRASIL, Ministério da Educação, Instituto Nacional de Estudos e Pesquisas Educacionais Anísio Teixeira. Censo escolar, 2003. Dis- 
ponível em: <http:/www.inep.gov.br/basic/censo escolar/sinopse/ 1996 e 2003>. Acesso em: 12 dez. 2005.

BRASIL, Ministério da Educação, Secretaria de Educação Especial. Programa educação inclusiva: direito à diversidade, 2003. Disponível em: <http://portal.mec.gov.br/seesp>. Acesso em: 27 dez. 2005.

BRASIL, Ministério Público Federal, Fundação Procurador Pedro Jorge de Mello e Silva. O acesso de alunos com deficiência às escolas e classes comuns da rede regular. 2. ed. Brasília, DF: Procuradoria Federal dos Direitos do Cidadão, 2004.

BRASIL, Presidência da República, Secretaria Especial dos Direitos Humanos. Declaração de Salamanca e linha de ação sobre necessidades educativas especiais. Brasília, DF: Coordenadoria Nacional para Integração da Pessoa Portadora de Deficiência CORDE, 1997.

BUENO, José Geraldo Silveira. Educação especial brasileira integração/segregação do aluno diferente. São Paulo: EDUC/PUSP, 1993.

. A inclusão de alunos deficientes na classe comum

do ensino regular. Temas sobre Desenvolvimento, v. 9, n. 54, p. 21$27,2001$.

CHARLTON, James. Nothing about us without us. University of California Press, 2000.

CURY, Carlos Roberto Jamil. Os fora de série na escola. Campinas: Armazém do Ipê, 2005.

DECLARAÇÃO MUNDIAL SOBRE EDUCAÇÃO PARA TODOS. Plano de ação para satisfazer as necessidades básicas de aprendizagem. Tailândia, 1990. Disponível em:

<http://www.educacaoonline.pro.br/doc_declaracao_mundial_ sobre_educacao_para_todos.asp?f_id_artigo=2)>. Acesso em: 27 dez. 2005.

DENO, Evelyn. Special education as developmental capital. Exceptional Children, n. 37, p. 229-237, 1970.

EPSTEIN, Howard R. Means, ends, and the principle of normalization. A closer look. Education and training of the mentally retarded, v. 17, n. 2, p. 153-156, 1982. Disponível em: $<$ http://eric.ed.gov/ERICWebPortal/Home.portal?_nfpb=true\& _pageLabel=RecordDetails\&ERICExtSearch_SearchValue_0= EJ285502\&ERICExtSearch_SearchType_0=eric_accno\&objectId= $0900000 \mathrm{~b} 8014 \mathrm{c} 2 \mathrm{bb}>$. Acesso em: 27 dez. 2005.

EVANS, Peter. Educating students with special needs: a comparison of inclusion practices in OECD countries. Exceptional Children, Education Canada, v. 44, n. 11, p. 4-56, 2004.
FERGUSON, Dianne L.; FERGUSON, Philip M. The future of inclusive educational practice: construtive tension and the reform potencial for reflective reform. Childhood Education, v. 5, p. 302308, 1998.

FERREIRA, Júlio Romero. A exclusão da diferença: a educação do portador de deficiência. 2. ed. Piracicaba: Editora da UNIMEP, 1994. FUCHS, Doug.; FUCHS, Lynn S. Competing visions for educating students with disabilities: inclusion versus full inclusion. Childhood Education, Annual Theme, p. 309-316, 1998.

Inclusive schools movement and the radicalization of special education reform. Exceptional Children, v. 60, p. 294309, 1994.

FULLER, Bruce; CLARCK, Prema. Raising school effects while ignoring culture? Local conditions and the influence of classroom tools, rules, and pedagogy. Review of Educational Research, v. 12, n. 1, p. 119-157, 1994.

GARTNER, Alan; LIPSKY, Dorothy. Beyond special education: toward a quality system for all students. Harvard Educational Review, v. 57, p. 367-395, 1989.

HALLAHAN, Dan.; KAUFFMAN, James. Exceptional children. Introdution to special education. 6. ed. Boston: Allyn Bacon, 1994. HEGARTY, Seamus; POCKLINGTON, Keith; LUCAS, Dorothy. Educating pupils with special needs in the ordinary school. Windsor: NFER-Nelson, 1981.

JANNUZZI, Gilberta Sampaio de Martino. A educação do deficiente no Brasil: dos primórdios ao início do século XXI. Campinas: Autores Associados, 2004.

KIRK, Samuel A.; GALLAGHER, James John. Educating the exceptional children. 3. ed. Houghton Mifflin, 1979.

KRAUSE, Renate Frida. Educação da pessoa com deficiência em escolas comuns nos últimos 50 anos. Dissertação (Mestrado em Educação) - Centro de Educação, Universidade Federal de Santa Maria, Santa Maria, 2002.

LIPSKY, Dorothy; GARTNER, Alan. Inclusion and school reform: transforming America's classrooms. Baltimore: Paul H. Brookes, 1997.

MARTINS, Isabel. Entrevista com Peter Mittler. Inclusão escolar é transformação na sociedade. Presença Pedagógica, v. 5, n. 30, p. 5-16, 1999.

MATTOS, Nélson Dagoberto. Cidadania, deficiência e política educacional no estado de Sergipe: 1979-2001 Tese (Doutorado em Educação Especial) - Centro de Educação e Ciências Humanas. Universidade Federal de São Carlos, São Carlos, 2004. 
MAZZOTTA, Marcos José da Silveira. Políticas de educação especial no Brasil: da assistência aos deficientes à educação escolar. 1994. Tese (Livre-Docência em Educação) - Faculdade de Educação, Universidade de São Paulo, São Paulo, 1994.

MC CORD, William T. From theory to reality: obstacles to the implementation of the normalization principle in human services. Mental Retardation, v. 20, n. 6, p. 247-253, 1982.

MENDES, Enicéia Gonçalves; FERREIRA, Júlio Romero; NUNES, Leila Regina d'Oliveira de Paula. Integração/inclusão: o que revelam as teses e dissertações em educação e psicologia. In: NUNES SOBRINHO, Francisco de Paula (Org.). Inclusão educacional: pesquisas e interfaces. Rio de Janeiro: Livre Expressão, 2003. p. 98-149.

NIRJE, Bengt. The normalization principle and its human management implications. In: KUGEL, Robert B.; WOLFENSBERGER, Wolf. (Eds.). Changing patterns in residential services for the mentally retarded. Washington: President's Committee on Mental Retardation, 1969. Disponível em: 〈http://www.disabilitymuseum.org/lib/docs/1941.htm>. Acesso em: 17 jul. 2006.

O'BRIEN, John (1999). The Genius of the Principle Of Normalization. Responsives Systems Associates, Lithonia, GA.1999. Disponível em: <http://eric.ed.gov/ERICDocs/data/ ericdocs2/content_storage_01/0000000b/80/0d/74/3a.pdf >. Acesso em: 20 jul. 2006.

O'HANLON, Christine (Ed.). Inclusive education in Europe. London: Fulton, 1995.

ODEH, Muna Muhammad. O atendimento educacional para crianças com deficiências no hemisfério sul e a integração não-planejada: implicações para a proposta de integração escolar. Revista Brasileira de Educação Especial, v. 1, n. 6, p. 27-42, 2000.

PIJL, Sip Jan; MEIJER, Cor J. W. Does integration count for much? An analysis of the practices of the integration in eight countries. European Journal of Special Needs Education, v. 3, n. 2, p. 63-73, 1991.

PORTER, Gordon L. Meeting the challenge: inclusion and diversity in Canadian schools. Exceptional Children Education, v. 44, n. 1, p. 4-56, 2004.

REYNOLDS, Maynard Clinton; AINSCOW, Mel. Education of children and youth with special needs: an international perspective. In: HUSEN, Torsten.; POSTLETHWAITE, T. Neville (Eds.). The international encyclopedia of education. 2. ed. Oxford: Pergamon, 1991. p. 55-66.

\section{RMC RESEARCH CORPORATION/THE ACADEMY FOR} EDUCATIONALDEVELOPMENT/NATIONALASSOCIATION OF STATE DIRECTORS OF SPECIAL EDUCATION. Alignment of Special and General Education Reform in Comprehensive Scholl Reform Demonstration Programs: Literature Review. 2002. Disponível em: 〈http://www.dssc.org/CSRD/\#RES〉. Acesso em: 20 jul. 2006.

ROSA, Lígia Cardoso Silveira. Formação continuada de atendentes para a inclusão de crianças com necessidades educacionais especiais em creches. 2003. Dissertação (Mestrado em Educação Especial) - Centro de Educação e Ciências Humanas, Universidade Federal de São Carlos, São Carlos, 2003.

ROSENQVIST, Jerry. The concept of integration in school and society in connection with adult quality of life. In: Ease - 8. ed. Job Possibilities and Quality of Life for Handicapped People in Europe, v. 8, p. 41-47, 1994.

SAILOR, Wayne. Inclusion. President's Comission on Excellence in Special Education Research Agenda Task Force. Nashville. Tennessee, 2002. Disponível em: <http://www.beachcenter.org/ Books\%5CFullPublications \%5CPDF\%5CPresidentReport.pdf $>$. Acesso em: 23 jul. 2006.

SAILOR, Wayne; GEE, Kathy; KARASOFF, Patricia. Full inclusion and school restructuring In: Martha. E. SNELL (Ed.). Instruction of students with severe disabilities. Columbus, $\mathrm{OH}$ : Merrill, 1993. p. 1-30.

SALE, Paul; CAREY, Doris M. The sociometric status of students with disabilities in a full-inclusion school. Exceptional Children, v. 62 , n. 1, p. 6-19, 1995.

SANTOS, Núbia Aparecida Schaper. A perspectiva da inclusão escolar na educação infantil de Juiz de Fora. Dissertação (Mestrado em Educação Especial) - Centro de Educação e Ciências Humanas. Universidade Federal de São Carlos, São Carlos, 2002.

SCRUGGS, Thomas E.; MASTROPIERI, Margo A. Special Education for the $21^{\text {st }}$ Century - Integrating Learning - Strategies and thinking skills. Journal of Special Education, v. 27, n. 1, p. 1$15,1993$.

SÖDER, Marten. Mentally retarded children. Research and development concerning integration of handicapped pupils into the ordinary school system. Estocolmo: National Swedish Board of Education, 1980.

STAINBACK, Susan; STAINBACK, William. A rationale for the merger of special and regular education. Exceptional Children, v. 51, p. 102-111, 1984. 
A radicalização do debate sobre inclusão escolar no Brasil

TURNBULL, Rutherford; TURNBULL, Ann; SHANK, Marilyn; SMITH, Sean; LEAL, Dorothy. Exceptional lives: special education in today's schools. Columbus, OH: Merrill, 2002.

USA, National Commission on Excellence in Education. A nation at risk: the imperative educacional reform. Washington, DC, 1983. USA, United States Congress. Public Law 94-142 - Education for All Handicapped Children Act. Washington, DC, 1977.

WARNOCK REPORT. Special education needs. Report of the Committee of Inquiry into Education of Handicapped Children and Young People. London: HMSO, 1979.

WILL, Madeleine. Educating children with learning problems: a shared responsability. Exceptional Children, v. 52, p. 411-415, 1986 WOLFENSBERGER, Wolf. Social role valorization: a proposed new term for the principle of normalization. Mental Retardation, v. 21 , n. 6, p. 234-239, 1983.

. The principle of normalization in human services. Toronto: National Institute on Mental Retardation, 1972.

ENICÉIA GONÇALVES MENDES, doutora em psicologia pela Universidade de São Paulo, é professora do Programa de PósGraduação em Educação Especial da Universidade Federal de São Carlos. Publicações recentes: A pesquisa sobre inclusão escolar no Brasil: será que estamos caminhando de fato na busca de solu- ções para os problemas? (In: JESUS, Denise Meyrelles de; BAPTISTA, Claudio Roberto; VICTOR, Sonia Lopes (Orgs.). Pesquisa e educação especial: mapeando produções. Vitória: EDUFES, 2006. p. 155-176); Construindo um lócus de pesquisa sobre inclusão escolar (In: MENDES, Enicéia Gonçalves; ALMEIDA, Maria Amélia; WILLIAMS, Lúcia C.A. (Orgs.). Temas em educação especial: avanços recentes. São Carlos: EDUFSCar, 2004. p. 221-230); em co-autoria com FERREIRA, Júlio Romero e NUNES, Leila R. P. Integração/inclusão: o que revelam as teses e dissertações em educação e psicologia (In: NUNES SOBRINHO, Francisco de Paula (Org.). Inclusão educacional: pesquisas e interfaces. Rio de Janeiro: Livre Expressão, 2003. p. 98-149). Pesquisas em desenvolvimento: "Projeto SOS Inclusão: Consultoria colaborativa para professores e seus alunos com necessidades educacionais especiais" e "Projeto Alta TA\&Inclusão - viabilidade dos recursos de alta tecnologia assistiva para a escolarização inclusiva de alunos com severas disfunções motoras", ambos apoiados pelo CNPq. E-mail: egmendes@power.ufscar.br; eniceia.mendes@pesquisador.cnpq.br.

Recebido em janeiro de 2006

Aprovado em maio de 2006 


\section{Resumos/Abstracts/Resumens}

\section{Enicéia Gonçalves Mendes}

\section{A radicalização do debate sobre} inclusão escolar no Brasil

O debate sobre a inclusão escolar no Brasil tem se transformado cada vez mais num verdadeiro embate, provocando polêmica, estridência e polarização. Um de seus maiores impactos tem incidido na arena da educação especial, sendo um dos argumentos recorrentes a proposição de que a se trata de um novo paradigma que deverá alterar radicalmente a educação de crianças e jovens com necessidades educacionais especiais na realidade brasileira. A fim de "iluminar" mais do que "esquentar" este debate, proponho-me a contextualizar as raízes históricas desse movimento. Num segundo momento, examino os possíveis impactos da perspectiva da inclusão escolar e da inclusão total na realidade brasileira.

Concluo discutindo a tese de que temos de enfrentar o desafio de lidar com a contradição de uma ideologia importada que representa um alinhamento ao modismo, mas que ao mesmo tempo é um imperativo moral que pode ser uma das estratégias para superar problemas crônicos da educação especial no país. Palavras-chave: história da educação especial; integração; educação inclusiva; inclusão escolar; inclusão total

Radicalization of the debate on school inclusion in Brazil

The debate about school inclusion in
Brazil has become more and more a true collision, provoking controversy, stridency and polarization. One of the largest impacts is taking place in the arena of Special Education, in which one of the recurrent arguments is the proposition that deals with a new paradigm that should radically alter the education of children and youngsters with special educational needs in the Brazilian context. In order to "illuminate" rather than to "warm up" this debate, we intend, first, to contextualize the historical roots of the movement. Secondly, we examine the possible impacts of school inclusion and full inclusion on the Brazilian educational system. In conclusion, we discuss the thesis that we have to face the challenge of dealing with the contradiction of an imported ideology that represents an alignment to the latest fashion, but that at the same time can be one of the strategies used to overcome chronic problems of special education in the country.

Key words: history of special education; school integration; inclusive education; school inclusion; full inclusion

La radicalización del debate sobre inclusión escolar en Brasil

El debate sobre la inclusión escolar en Brasil se está tornando cada vez más en una verdadera adversidad, provocando polémica, estridencia y polarización. Uno de sus mayores im- pactos ha incurrido en la arena de la educación especial, siendo uno de los argumentos recurrentes la proposición de que se trata de un nuevo paradigma que deberá alterar radicalmente la educación de niños y jóvenes con necesidades educacionales especiales en la realidad brasileña. Con fin de "iluminar" más de que "exaltar" este debate, me propongo a contextualizar las raíces históricas de este movimiento. En un segundo momento, examino los posibles impactos de la perspectiva de la inclusión escolar y de la inclusión total en la realidad brasileña. Concluyo discutiendo la tesis de que tenemos que enfrentar el desafío de lidiar con la contradicción de una ideología importada que representa una alineación al modismo, pero que al mismo tiempo es un imperativo moral que puede ser una de las estrategias para superar problemas crónicos de la educación especial en el país.

Palabras claves: historia de la educación especial; integración; educación inclusiva; inclusión escolar; inclusión total 